\title{
Do motor performance and specific-skill tests discriminate technical efficiency in small-sided games?
}

\author{
Julio Cesar da Costa $^{1}$ (D), Paulo Henrique Borges ${ }^{1}$ (D), Luiz Fernando Ramos-Silva ${ }^{1}$ (D), \\ Vinícius Muller Reis Weber ${ }^{1}$ (D), Felipe Arruda Moura ${ }^{2}$ (D), Alexandre Moreira ${ }^{3}$ (D), \\ Enio Ricardo Vaz Ronque ${ }^{1}$ \\ ${ }^{1}$ Universidade Estadual de Londrina, Centro de Educação Física e Esporte, Laboratório de \\ Atividade Física e Saúde, Londrina, PR, Brasil; ${ }^{2}$ Universidade Estadual de Londrina, Centro de \\ Educação Física e Esporte, Departamento de Ciência do Esporte, Londrina, PR, Brasil; \\ ${ }^{3}$ Universidade de São Paulo, Departamento de Esporte, Escola de Educação Física e Esporte, \\ São Paulo, SP, Brasil.
}

Associate Editor: Mariana Ferreira de Souza, UNIVASF, Petrolina, PE, Brasil.

\begin{abstract}
Aim: The aim was to compare performance in specific-skill tests and motor coordination between groups with different technical efficiency and verify possible variables related to specific skills and motor coordination that contribute to discriminate players into high- and low-technical efficiency. Methods: The sample consisted of 82 young soccer players (12-15 years). Body size, bone age, motor performance tests, soccer-specific skill tests, and frequency of technical actions in SSG were analyzed. Statistic cluster-derived ANOVA F was used to identify which variables related to technical action most contributed to classifying subjects with similar performance. Discriminant analysis (Stepwise Method) was used to verify which predictor variables discriminated players into groups of low- and high-frequency technical actions in SSG. Statistical significance was set at 5\%. Results: The group of high technical efficiency presented better performance in motor tests, shuttle run $(P=0.04$; ES $=-0.55)$, jumping laterally $(P=0.02 ; \mathrm{ES}=0.58)$, kicking speed $(P=0.03$; ES $=0.60)$, soccer-specific skill tests, leading the ball in a straight line (LBSL) $(P=0.01$; $\mathrm{ES}=-0.75)$, and zig-zag ball control $(\mathrm{ZZBC})(P=0.04$; $\mathrm{ES}=-0.55)$; variable leading the ball in a straight line correctly discriminated $60 \%$ of players into high- and low-frequency groups. Conclusion: The frequency of technical actions in SSG was poorly influenced by motor performance and specific skill tests, and only the LBSL test correctly classified players of different frequencies of technical actions in SSG.
\end{abstract}

Keywords: soccer, motor performance, technical skills, athletic performance.

\section{Introduction}

Soccer is one of the sport most widely practiced in the world and the inclusion of youth athletes has increased in selection processes $^{1,2}$. In this sense, researchers have attempted to find indicators that can be used as references when discriminating talented players ${ }^{3-7}$.

Technical qualities performed during the match have been pointed out as one of the main indicators during the process of prospecting and selecting talents, as the correct execution of movements can be a decisive factor to achieve success in the game ${ }^{8}$. Despite the need to include technical performance and motor coordination analyses in studies with young soccer players, other factors need to be pointed out, like the fact of the lack of standardization tests and the variety of procedures available seem to be limitations in comparing research results and the consequent advances in understanding this issue $\mathrm{Ali}^{8}$.
In this sense, researchers involved in the understanding of the formation of young players commonly adopt a battery of specific tests to evaluate motor coordination and technical skills ${ }^{9,10}$; tests that, although they present a moderate correlation between the tests of specific skills with technical performance ${ }^{11,12}$ and motor performance ${ }^{13,14}$ present little or no relation with the real situation of the game, since, do not represent the real complexity in games due to their low ecological validity ${ }^{15}$. Blomqvist, Vanttinen, and Luhtanen ${ }^{16}$ reported that these batteries usually do not demonstrate the player's ability to perform skills in a real game situation. It occurs mainly because soccer is a complex phenomenon ${ }^{17,18}$, i.e., when isolating some factor to be analyzed, the information could be lost since the modality is marked by the interaction between different domains ${ }^{19,20}$.

In addition to the number of published studies applying specific skills $^{4,10}$ and motor coordination 
tests $^{13,14}$ with youth athletes, it is important to understand whether the results obtained by these batteries help coaches to identify talented players and to discriminate players with high technical efficiency in a real game situation. Based on our knowledge, the relative contribution of motor coordination and specific skill batteries to technical efficiency is unknown among young players, a period in which coaches need to find indicators to assess individual and collective progress during training sessions ${ }^{16}$.

These tests may help coaches and researchers to verify the real validity in the use of specific skills and motor coordination tests to evaluate young athletes. Given this scenario, our initial hypothesis was that specific skill batteries and motor coordination tests do not discriminate players into groups of high- or low-technical efficiency, since their low ecological validity would bring low relation with real play situations ${ }^{15}$.

Therefore, the aims of this study are a) to compare performance in specific skill tests and motor coordination between groups with different technical efficiency; and b) verify which variables related to specific skills and motor coordination contribute to discriminate players into highand low-technical efficiency.

\section{Materials and Methods}

\section{Experimental Approach to the Problem}

A cross-sectional design was used in the present study. Data collection was performed in the morning. Anthropometry, motor coordination tests, soccer-specific skill tests, and frequency of technical actions in smallsided games were analyzed, and discriminant analysis was used to observe whether performance in motor tests and soccer-specific skills could discriminate players into highand low-frequency of technical actions in SSG.

\section{Participants}

Initially, were recruited for the study 97 young soccer athletes, with the exclusion criteria, the final sample was of 85 athletes belonging to two youth soccer schools from Londrina, Paraná, Brazil. Sample characteristics are described in Table 1. Players and their parents or legal guardians were informed and written consent was obtained before participation. The study was conducted in accordance with the resolution of the National Health Council (466/2012) and was approved by the Research Ethics Committee of the local University (Proc. 2.650.232/2018). Written informed consent was obtained from each participant and their respective parents/guardians; players gave written assent according to the Child and Adolescent Statute. The following inclusion criteria were adopted: I) Players should be enrolled in soccer schools; II) Not be in a pre-evaluation period in schools, and III) Free from any kind of injury during the evaluation
Table 1 - Characteristics of the participants by groups of High- and Lowfrequency of technical actions.

\begin{tabular}{lcccccc}
\hline Variables & \multicolumn{3}{c}{ Technical efficiency index } & \multirow{2}{*}{ T-test } & P \\
\cline { 2 - 4 } & $\begin{array}{c}\text { General } \\
(\mathbf{n}=\mathbf{8 2})\end{array}$ & $\begin{array}{c}\text { High } \\
(\mathbf{n}=\mathbf{1 7})\end{array}$ & $\begin{array}{c}\text { Low } \\
(\mathbf{n = 6 5})\end{array}$ & & \\
\hline Age (years) & $14.4(1.1)$ & $14.5(1.0)$ & $14.3(1.1)$ & 0.56 & 0.57 \\
$\begin{array}{l}\text { Experience level } \\
\text { (years) }\end{array}$ & $6.5(2.3)$ & $6.5(2.1)$ & $6.5(2.3)$ & -0.01 & 0.99 \\
Height (cm) & $57.9(10.3)$ & $56,9(9.0)$ & 58.2 & -0.45 & 0.65 \\
& & & $(10.7)$ & & \\
Body mass (kg) & $169.6(10.0)$ & 168.2 & 169.9 & -0.65 & 0.52 \\
& & $(8.9)$ & $(10.3)$ & & \\
\hline
\end{tabular}

period. Injured players, those dismissed by schools, or those who dropped out during the data collection period were excluded from the sample. Thus, the data of 15 players who did not meet these criteria were taken from the sample.

\section{Anthropometry}

Body mass was evaluated using a digital scale, Seca 813 , Brazil, with an accuracy of $0.1 \mathrm{~kg}$, and height using a portable stadiometer, Harpenden, United Kingdom, with an accuracy of $0.1 \mathrm{~cm}$, according to criteria described by Gordon et al. ${ }^{21}$. Chronological age (CA) was defined in centesimal form, and calculated through the difference between birth date and evaluation date.

\section{Small-sided games}

As small-sided games (SSG) have been proposed to be useful as talent identification/monitoring tools ${ }^{1}$ and to mimic the game demands while developing technical and decision-making skills ${ }^{22}$, this training modality was used to evaluate technical actions. In this study, SSG used a three-a-side format $(3 \times 3$ plus a goalkeeper) as used in a previous study with young players ${ }^{23,24}$. The numerical configuration $(3 \times 3)$ was chosen as it represents the minimum structure that guarantees the characteristics of the official game ${ }^{25}$. Players were largely familiarized with this SSG format, as it has been regularly used in their training routines. Before starting the game, players were required to play according to official rules. Two halves of $4 \mathrm{~min}$ each were performed. The pitch area adopted measured $36 \mathrm{~m}$ in width $\times 27 \mathrm{~m}$ in length ${ }^{1,24,25}$. Passive recovery of 1 min was allowed between halves. Each team was formed by a defense player (center-back or left or right-back), a midfielder (defensive or offensive middle field), and a forward (center-forward or striker), distributed in each team according to their overall standings in their age-category in specific skills performance in field tests (leading the ball in a straight line, zig-zag ball control, back and forth ball control, pass and kick accuracy $)^{26,27}$. This counterbalanced procedure was adopted to allow similar technical performance conditions between teams. 


\section{Technical actions in small-sided games}

The frequency of technical actions was recorded during the SSG using one camera (Casio EX-10, $30 \mathrm{~Hz}$ frequency acquisition, São Paulo - Brazil) located $6 \mathrm{~m}$ above and to one side of the long axis of the pitch, at a distance of $15 \mathrm{~m}$ from the pitch. Lince software was used to code SSG technical actions. The frequency of the following technical actions was recorded: conquering the ball $(\mathrm{CB})$, receiving the ball $(\mathrm{RB})$, playing a neutral ball $(\mathrm{NB})$, losing the ball (LB), playing an offensive ball (OB), and successful goal attempts (SS) ${ }^{28}$. CB was considered when a player performed interception or tackle, regaining ball possession after an unsuccessful goal attempt from the opponent team; RB was considered when a player received the ball from a teammate and did not lose the ball control immediately after receiving it; NB was considered when performing a pass to a teammate, but without increasing the chance of goal attempt or imposing any disturbance to the opponent defense system; LB was considered when the player lost ball control (ball possession) without attempting a goal; OB was considered when performing a pass to a teammate, leading to a clear disturbance to the opponent defense system, while leading to a goal attempt; and SS was considered when a successful goal attempt occurred when the attacking team retained ball possession even after a goal attempt.

\section{Motor performance}

To evaluate motor performance, the battery of tests proposed by Luz et al. ${ }^{29}$ was used, which proposes six tests to evaluate locomotion, balance, and manipulation. For locomotion, Shuttle-run and distance jump tests were applied. To evaluate balance, platform displacement and lateral jump tests were performed; and for manipulation, throwing speed and kicking speed tests were performed. Subjects were familiarized with tests through an attempt performed prior to evaluation. The 2D analysis (two kicks, and two throws) were recorded by a camera, model Casio EX-10 (Cassio - São Paulo - Brazil), at an adjusted rate of $240 \mathrm{~Hz}$ and laterally positioned at a distance of $5 \mathrm{~m}$ from the central test area to allow observation of the ball trajectory. Space, where the subjects performed the tasks, was calibrated using four metal hastes, in an area of $2.0 \times 1.6 \mathrm{~m}$ square, with eight known Cartesian coordinate points. The $y$-axis was horizontal (pointing to the goal center), the $\mathrm{z}$ axis vertical (pointing up), and the $\mathrm{x}$-axis the cross product of $y$ and $z$ (pointing laterally) ${ }^{30}$. For calculation of the throwing and kicking speed, 2D images were reconstructed using the Dvideo Software ${ }^{31}$. The first ten frames after the last favorite hand or foot lost contact with the ball were used for reconstruction. 2D distances covered by the ball were calculated using the Microsoft Excel software and estimated through the calculation of the Euclidean distance and distance in meters per second $(\mathrm{m} / \mathrm{s})$ and the peak speed achieved in each attempt was considered, but only the highest peak between the two attempts was used for analysis. This analysis presented an accuracy of $6.09 \mathrm{~mm}^{32}$.

\section{Soccer-specific skills}

To evaluate performance in soccer-specific skills, the tests proposed by Mor and Christian ${ }^{27}$ and by the Portuguese Football Federation ${ }^{26}$ were adopted. Based on these protocols, four technical tests were used: leading the ball in a straight line (LBSL) and zig-zag ball control (ZZBC), proposed by the Portuguese Football Federation, and pass accuracy (PA) and kick accuracy (KA). Subjects were familiarized with tests through an attempt performed prior to evaluation.

\section{Statistical Analysis}

Data are described as mean and standard deviation. The Kolmogorov-Smirnov test was used to evaluate data normality. Non-Hierarch Cluster K-means multivariate analysis was used to classify players into two groups according to the Technical efficiency index performed during SSG. To identity which technical action variables most contributed to classifying subjects with similar performance, the statistic cluster-derived ANOVA $\mathrm{F}$ was used, as described previously ${ }^{33}$. $\mathrm{CB}(\mathrm{F}=73.02 ; \mathrm{p}=0.01)$, OB $(F=10.16 ; p=0.01)$, and SS $(F=23.05 ; p=0.01)$ variables presented significance and were therefore adopted to differentiate groups into two Clusters: Low $(n=65)$ and High $(n=17)$ technical efficiency index during SSG. The differences were compared by the independent t-Test and the Effect Size was evaluated by the $g$ de Hedges Test. Discriminant analysis (Stepwise Method) was used to verify which predictor variables (locomotion, balance, manipulation, LBSL, ZZBC, PA, and KA) discriminated players into groups of high- and low- frequency of technical actions in SSG. Bivariate correlations between independent variables were performed for collinearity diagnosis. All values found were located below 0.75 , indicating that none of the variables should be removed from the analysis ${ }^{33}$. The significance adopted was $5 \%$ and the software used was SPSS 24.0 (SPSS, Inc., Chicago, IL).

\section{Results}

Table 2 presents the results of technical actions during small-sided games, motor performance, and soccerspecific skills according to technical efficiency group. High $(\mathrm{n}=17)$ and low $(\mathrm{n}=65)$ performance groups demonstrated differences in the shuttle run $(P=0.04$; $\mathrm{ES}=-0.55)$, jumping laterally $(P=0.02 ; \mathrm{ES}=0.58)$, kicking speed $(P=0.03$; ES $=0.60)$, LBSL $(P=0.01$; $\mathrm{ES}=-0.75)$, and ZZBC $(P=0.04 ; \mathrm{ES}=-0.55)$ tests.

The result of the discriminant analysis revealed that LBSL predicted the technical action frequency during 
Table 2 - Technical actions, motor performance, and specific skills for groups of High- and low-frequency of technical actions (Mean and SD).

\begin{tabular}{|c|c|c|c|c|c|c|}
\hline \multirow[t]{2}{*}{ Motor performance and specific skills } & \multicolumn{3}{|c|}{ Technical efficiency index } & \multirow[t]{2}{*}{ T-test } & \multirow[t]{2}{*}{$P$} & \multirow[t]{2}{*}{ Effect Size } \\
\hline & General $(n=82)$ & High $(n=17)$ & Low $(n=65)$ & & & \\
\hline CB (No. of actions) & $1.9(1.5)$ & $2.2(1.9)$ & $1.8(1.4)$ & 0.87 & 0.39 & 0.23 \\
\hline RB (No. of actions) & $10.6(3.5)$ & $15.3(2.4)$ & $9.4(2.7)$ & 8.31 & $<0.01^{*}$ & 2.24 \\
\hline NB (No.of actions) & $6.7(3.0)$ & $10.0(2.5)$ & $5.9(2.5)$ & 6.13 & $<0.01 *$ & 1.65 \\
\hline LB (No.of actions) & $2.6(1.7)$ & $2.8(1.5)$ & $2.6(1.8)$ & 0.31 & 0.75 & 0.08 \\
\hline OB (No. of actions) & $1.9(1.6)$ & $2.8(1.5)$ & $1.7(1.5)$ & 2.84 & $<0.01 *$ & 0.87 \\
\hline SS (No. of actions) & $2.1(1.6)$ & $3.7(2.0)$ & $1.6(1.2)$ & 5.41 & $<0.01 *$ & 1.47 \\
\hline Shuttle run (s) & $10.1(0.5)$ & $9.8(0.4)$ & $10.2(0.6)$ & -2.11 & $0.04 *$ & -0.57 \\
\hline Standing Long Jump (cm) & $192.9(18.5)$ & $196.3(9.4)$ & $192.0(20.2)$ & 1.28 & 0.20 & 0.35 \\
\hline Jumping laterally (No. of actions) & $46.0(7.3)$ & $49.3(6.2)$ & $45.2(7.4)$ & 2.12 & $0.02 *$ & 0.57 \\
\hline Shifting platforms (No. of actions) & $10.2(1.4)$ & $10.1(1.4)$ & $10.2(1.5)$ & -0.32 & 0.75 & -0.09 \\
\hline Throwing speed $(\mathrm{km} / \mathrm{h})$ & $58.5(8.0)$ & $61.7(7.5)$ & $57.7(7.9)$ & 1.89 & 0.06 & 0.51 \\
\hline Kicking speed (km/h) & $68.4(7.7)$ & $72.0(8.1)$ & $67.5(7.4)$ & 2.18 & $0.03 *$ & 0.59 \\
\hline LBSL (s) & $14.9(1.0)$ & $14.4(0.7)$ & $15.1(1.0)$ & -2.64 & $0.01 *$ & -0.71 \\
\hline ZZBC (s) & $19.6(1.5)$ & $18.9(1.2)$ & $19.7(1.6)$ & -2.03 & $0.04 *$ & -0.55 \\
\hline PA (points) & $4.4(2.0)$ & $4.7(1.9)$ & $4.4(2.0)$ & 0.58 & 0.56 & 0.16 \\
\hline KA (points) & $65.7(23.4)$ & $68.4(23.5)$ & $65.1(23.5)$ & 0.52 & 0.60 & 0.14 \\
\hline
\end{tabular}

Note: $\mathrm{CB}=$ conquering the ball; $\mathrm{RB}=$ receiving the ball; $\mathrm{NB}=$ playing a neutral ball; $\mathrm{LB}=$ losing the ball; $\mathrm{OB}=$ playing an offensive ball; $\mathrm{SS}=$ executing a successful shot; $\mathrm{LBSL}=$ leading the ball in a straight line; $\mathrm{ZZBC}=$ zig-zag ball control; $\mathrm{PA}=$ pass accuracy; KA $=$ kick accuracy; $*=\mathrm{P}<0,05$.

small-sided games (Table 3), correctly classifying 59.8\% of players of low- and high-frequency technical actions.

\section{Discussion}

This study aimed to compare performance in specific skill tests and motor coordination between groups with different technical efficiency, and verify which variables related to specific skills and motor coordination contribute to discriminate players into high- and low-technical efficiency. The main results point out that the group of hightechnical efficiency presented a better performance in motor tests (shuttle run, jumping laterally, and kicking speed) and soccer-specific skill tests (LBSL and ZZBC). Data suggest that these variables can differentiate the technical performance of young soccer players, at least when the referred technical performance is measured based on the frequency of technical actions. However,

Table 3 - Discriminant analysis for prediction of technical actions in small-sided games.

\begin{tabular}{lc}
\hline & Function \\
\hline Canonical correlation & 0.28 \\
Wilks' Lambda & 0.92 \\
Variance explained (\%) & 100 \\
Model cross-validation (\%) & 59.8 \\
Significance & $0.01^{*}$ \\
Selected variable & LBSL \\
\hline
\end{tabular}

Note: $\mathrm{LBSL}=$ leading the ball in a straight line; $*=\mathrm{P}<0,05$. using only the LBSL test could correctly classify almost $60 \%$ of young athletes of high- and low- frequency of technical actions.

Studies that have sought to evaluate the influence of motor tests on technical actions in match-play are scarce, which brings a certain degree of limitation when comparing the current results with previous investigations. Rubajczyk and Rokita ${ }^{11}$ evaluated U12 and U15 players, and a weak inverse relationship was found for U15 $(\mathrm{r}=-0.33)$ and a moderate inverse relationship for $\mathrm{U} 12$ $(\mathrm{r}=-0.57)$ between ball conduction and ball control tests with technical performance; suggesting that performance could be associated with the maturational process, which in turn may influence maximum running speed in young soccer players. Talović et al. ${ }^{12}$ evaluated soccer players aged around 14 years of age and demonstrate a d significant relationship between technical performance and 20 -m running $(\beta=0.34)$, ball control with both legs $(\beta=0.23)$ and sit and reach tests $(\beta=-0.27)$.

However, when athletes were divided into groups of high- and low-technical efficiency, a significant difference was observed in the performance of motor tests and specific skills, with moderate effect size. Additionally, LBSL emerged as a variable that could discriminate technical efficiency during SSG, differentiating players with better performance in the game. Interestingly, Lulzim ${ }^{34}$ observed a significant relationship between performance in the LBSL test $(r=0.82)$ and ball control with a change of directions $(r=0.34)$ with the $25-\mathrm{m}$ running test. These results suggest that performance on this type of test may 
be associated with the ability of young players to generate power and to run with the ball.

Likewise, Leyhr et al. ${ }^{35}$ evaluated 1,134 young German soccer players and showed a variance of $50.2 \%$ with the $20 \mathrm{~m}$ running test and performance of $32.6 \%$ in the ball control test, with the entry of these young players into clubs belonging to the German Football League. In other words, athletes with high performance in basic categories through leading the ball at speed tests are more likely to be listed as possible elite athletes. This information is important, especially for professionals linked to the process of training and selection of young soccer players since only a simple field test could differentiate the technical potential of young players.

Taking into account the results of this study together with those of the abovementioned studies, it would be reasonable to infer that the LBSL test tends to correlate, given some degree of variation, with the technical efficiency of young athletes. However, further studies should seek to understand the influence of motor aspects and specific skill tests in the technical performance of young athletes, since these relationships tend to be weak since other factors could influence technical performance during soccer matches $^{34,35}$. One possible reason for these relationships may be the fact that LBSL involves characteristics inherent to speed displacement and the ability to control the ball, which are aspects that make up the physical and motor performance.

The present findings suggest that the group of hightechnical efficiency in SSG presents a better performance in motor testing (shuttle run, jumping laterally, and kicking speed) and specific skills in soccer (LBSL and ZZBC). However, the hypothesis that there is multicollinearity among predictor variables could be raised, which could influence the results, and that due to this possibility, caution is needed to generalize the findings. Another possible explanation for the present findings; however, maybe the complexity of a soccer match, in which many factors interact to induce performance. Technical actions; therefore, can be affected by the interaction of physical, tactical, cognitive, and emotional elements, which in turn impose a high degree of complexity on the system and, consequently, on performance ${ }^{36}$.

These aspects, which are inherent to the game, reveal the difficulty in discriminating isolated factors that could influence technical performance in soccer. However, the results of this study suggest that technical actions evaluated in a more ecological context (SSG performance) can be predicted by changes in LBSL performance, and less by other motor and specific skill tests. Thus, the application of several engine tests and specific skill testing protocols would not be necessary, as well as their correlation with the technical performance during games, since by performing only one test, LBSL, it would be possible to identify athletes who would perform best during games, thus seeking standardization in the evaluation of these contexts. The cross-sectional design and the use of only one SSG session are study limitations.

\section{Conclusion}

Our findings suggest that the group of high-technical efficiency in SSG presented a better performance in motor performance (shuttle run, jumping laterally, and kicking speed) and soccer-specific skill tests (LBSL and ZZBC). The LBSL test correctly discriminated players into lowand high-technical efficiency index, indicating that the frequency of technical actions in this age group may be related to the ability to run with the ball.

\section{References}

1. Unnithan V, White J, Georgiou A, Iga J, Drust B. Talent identification in youth soccer. J Sports Sci. 2012;30:19-26.

2. Westerståhl M, Barnekow-Bergkvist M, Hedberg G, Jansson E. Secular trends in sports: participation and attitudes among adolescents in Sweden from 1974 to 1995. Acta Paediatr. 2003;92:602-9.

3. Coelho-e-Silva MJ, Figueiredo AJ, Simoes F, Seabra A, Natal A, Vaeyens R, et al. Discrimination of U-14 Soccer Players by Level and Position. Int $\mathrm{J}$ Sports Med. 2010;31:790-96.

4. Figueiredo AJ, Coelho-e-Silva MJ, Malina RM. Predictors of functional capacity and skill in youth soccer players. Scand J Med Sci Sports. 2011;21:446-54.

5. Williams AM, Reilly T. Talent identification and development in soccer. J Sports Sci. 2000;18:657-67.

6. Larkin P, O'Connor D. Talent identification and recruitment in youth soccer: Recruiter's perceptions of the key attributes for player recruitment. PLoS One. 2017;12:e0175716.

7. Figueiredo AJ, Coelho-e-Silva MJ, Sarmento H, Moya J, Malina RM. Adolescent characteristics of youth soccer players: do they vary with playing status in young adulthood? Res Sports Med. 2020;28:1-12.

8. Ali A. Measuring soccer skill performance: A review. Scand J Med Sci Sports. 2011;21:170-83.

9. Gouvêa MAD, Cyrino ES, Valente-Dos-Santos J, Ribeiro AS, Silva DRPD, Ohara D, et al. Comparison of skillful vs less skilled young soccer players on anthropometric, maturation, physical fitness and time of practice. Int J Sports Med. 2017;38:384-95.

10. Rechenchosky L, Borges PH, Menegassi VM, Deprá PP, Ronque ERV, Rinaldi W. What are the implications of controlling anthropometric variables when comparing technical skills and physical fitness in young soccer regional players? J Phys Educ and Sport. 2017;17:758-63.

11. Rubajczyk K, Rokita A. Relationships between results of soccer-specific skill tests and game-related soccer skill assessment in young players aged 12 and 15 years. Trends Sport Sci. 2015;22:197-206.

12. Talović M, Rađo I, Jelesković E, Alić H. The effect of basic motor abilities on the success in football game of football players Aged 13 to 15-year-old. Homo Sporticus. 2010;12:42-5. 
13. Deprez DN, Fransen J, Lenoir M, Philippaerts RM, Vaeyens R. A retrospective study on anthropometrical, physical fitness, and motor coordination characteristics that influence dropout, contract status, and first-team playing time in highlevel soccer players aged eight to eighteen years. J Strength Cond Res. 2015;29:1692-704.

14. Milenković D, Stanojević I. Accuracy in football: Scoring a goal as the ultimate objective of the football game. Int $\mathrm{J}$ Cognitive Res Sci Eng and Educ. 2013;1:33-7.

15. Aquino R, Marques RFR, Petiot GH, Goncalves LGC, Moraes C, Santiago PRP, et al. Relationship between procedural tactical knowledge and specific motor skills in young soccer players. Sports. 2016;4:1-10.

16. Vänttinen T, Blomqvist M, Häkkinen K. Development of body composition, hormone profile, physical fitness, general perceptual-motor skills, soccer skills, and on-the-ball performance in soccer-specific laboratory test among adolescent soccer players. J Sport Sci \& Med. 2010;9:547-56.

17. Garganta J, Gréhaigne JF. Abordagem sistêmica no futebol: moda ou necessidade? Movimento. 1999;5:40-50.

18. Borges PH, Garganta J, Guilherme J, Jaime MO, Menegassi VM, Rechenchosky L, et al. Tactical efficacy and offensive game processes adopted by Italian and Brazilian youth soccer players. Motriz: J Phys Ed. 2019;25:e101922.

19. Clemente FM, Martins FML, Wong DP, Kalamaras D, Mendes RS. Midfielder as the prominent participant in the building attack: A network analysis of national teams in FIFA World Cup 2014. Int J Perform Anal Sport. 2015;15:704-22.

20. Praça GM, Lima BB, Bredt SDGT, Sousa RBE, Clemente FM, Andrade AGP. Influence of match status on players' prominence and teams' network properties during the 2018 FIFA World Cup. Front Psychol. 2019;28:1-8.

21. Gordon CC, Chumlea WC, Roche AF. Stature, recumbent length, and weight. In: Anthropometric standardization reference manual. Champaign, Human Kinetics Books; 1988. p.3-8.

22. Harrison CB, Gill ND, Kinugasa T, Kilding AE. Quantification of physiological, movement, and technical outputs during a novel small-sided game in young team sport athletes. $\mathrm{J}$ Strength Cond Res. 2013;27:2861-68.

23. Halouani J, Chtourou H, Gabbett T, Chaouachi A, Chamari K. Small-sided games in team sports training: a brief review. J Strength Cond Res. 2014;8:3594-618.

24. Sannicandro I, Cofano G. Small-sided games in young soccer players: physical and technical variables. MOJ Sports Med. 2017;1:1-4.

25. Garganta J. Competências no ensino e treino de jovens futebolistas. Lecturas. 2002;8:1-15.

26. FPF. Habilidades e destrezas do futebol:“ os skills do futebol”. Lisboa: Federação Portugues de Futebol, 1986.
27. Mor D, Christian V. The development of a skill test battery to measure general soccer ability. NCJ Health Phys Educ. 1979;15:30-9.

28. Grehaigne J, Godbout P, Bouthier D. Performance assessment in team sports. J Teach Phys Educ. 1997;16:500-16.

29. Luz C, Rodrigues LP, Almeida G, Cordovil R. Development and validation of a model of motor competence in children and adolescents. J Sci Med Sport. 2016;19:568-72.

30. Milioni F, Vieira LHP, Barbieri RA, Zagato AM, Nordsborg NB, Barbieri FA, et al. Futsal match-related fatigue affects 2 running performance and neuromuscular 3 parameters but not finishing kick speed or 4 accuracy. Front Physiol. 2016;7:1-10.

31. Figueroa PJ, Leite NJ, Barros RML. Background recovering in outdoor image sequences: an example of soccer players segmentation. Image Vis Comput. 2006;24:363-74.

32. Barbieri FA, Gobbi LT, Santiago PR, Cunha SA. Performance comparisons of the kicking of stationary and rolling balls in a futsal context. Sports Biomech. 2010;9, 1-15.

33. Maroco J. Editor. Análise estatística com o SPSS Statistics. Ed. Edições Silabo Ltda, Lisboa, 2014.

34. Lulzim I. Canonical relation of morphological characteristics and motor abilities of young football players. Res Kinesis. 2013;41:87-91.

35. Leyhr D, Kelava A, Raabe J, Hoèner O. Longitudinal motor performance development in early adolescence and its relationship to adult success: An 8-year prospective study of highly talented soccer players. PLoS One. 2018;13: e0196324.

36. Huijgen BCH, Elferink-Gemser MT, Ali A, Visscher C. Soccer skill development in talented players. Int J Sports Med. 2013;34:720-26.

\section{Corresponding author}

Julio Cesar da Costa. Londrina State University. Physical Activity and Health Laboratory, Center of Physical Education and Sports, Rodovia Celso Garcia Cid, Km 380, University Campus, P.O. box 6001, Londrina, Paraná, Brazil, Zipcode: 86051-990. Telephone: +55 (43) 33714139.

E-mail: juliocostaweb@gmail.com.

Manuscript received on August 22, 2020

Manuscript accepted on December 8, 2020

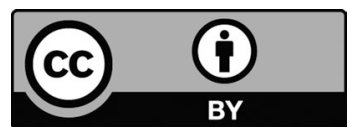

Motriz. The Journal of Physical Education. UNESP. Rio Claro, SP, Brazil - eISSN: 1980-6574 - under a license Creative Commons - Version 4.0 